\title{
Optimum Location and The Theory of Production: A Comparative Static Analysis ${ }^{\dagger}$
}

\author{
Amir Khalili and Abbas Mirakhor**
}

\section{INTRODUCTION}

Location theory of the firm in a simple context was pioneered by Weber [8], whose analysis involved a firm with fixed coefficient technology attempting to determine the profit maximizing location with respect to input sources and market location. The optimum location was determined to lie somewhere within the triangle formed by linking the market point with two input sources and the two input sources with each other.

In the early fifties, Isard [3] established the compatibility of much of spatial theory with the substitution principle of general economics. Moses [6], in 1958 , published a geometric analysis elucidating the location principles of a Weber-type problem when production technology is described by a variable proportions relationship with variable returns to scale. Moses' main conclusions were that the profit maximizing location of the firm for the case of locational straight line requires a proper adjustment of output, input combination, location and price, and that the optimum location probably would not correspond to the point of minimum transport cost.

In 1967, Sakashita [7] attempted to approach Moses' problems analytically by restricting his analysis to include only linearly homogeneous production functions and the case of locational straight line and hence, limiting the generality of his conclusions.

In 1971, Bradfield [1] showed that given Moses' assumptions, a single optimal location can be obtained at any level of output if the production function is homogeneous of any degree greater than zero. In 1973, Emerson [2] offered a model for carrying out further analysis of the case of locational straight line.

In 1974, Khalili, et al. [4] determined the conditions for cost minimizing optimum production locations for the case of Weber's locational triangle. In 1978, Miller and Jensen [5] derived the conditions for profit maximizing optimum location for a Moses-type problem, in which they derived the condi-

\footnotetext{
** Associate Professor of Economics, Cleveland State University and Professor of Economics, Alabama A\&M University, respectively.
}

†The authors would like to thank an anonymous referee for helpful comments and suggestions. 
tions under which location decision is independent of output and also showed the conditions under which the location problem may have an interior, a corner, or an "on a line" solution.

This paper uses the methods presented by Khalili, et al. It is a comparative static analysis of the locational problem of a profit maximizing firm in which the effect of several changes in the exogenous variables on the locational decision of the firm with and without prior locational constraint are determined. Specifically, it formulates a profit maximization location problem and analyzes the effect of changes in output price, output transport rates and input prices on the location decision with and without prior constraint on the location distance from the market.

\section{THE PROBLEM}

The "locational problem" can be posed as follows: a one-plant single-product firm, operating under conditions of perfect competition in product as well as in input markets, must find a profit maximizing production location. It uses two transportable inputs, $\mathbf{M}_{1}$ and $\mathrm{M}_{2}$, and supplies its product to a consumption center, $M_{3}$ (see Fig. 1 in [4], p. 467). Mathematically the problem can be formulated as follows:

$$
\begin{gathered}
\max . \pi=\mathrm{TR}-\mathrm{TC}= \\
\mathrm{P}_{\mathrm{o}} \mathrm{F}\left(\mathrm{M}_{1}, \mathrm{M}_{2}\right)-\left(\mathrm{P}_{1}+\mathrm{r}_{11} \mathrm{~S}\right) \mathrm{M}_{1}-\left(\mathrm{P}_{2}+\mathrm{r}_{22} \mathrm{~S}\right) \mathrm{M}_{2}-\mathrm{r}_{\mathrm{o}} \mathrm{hF}\left(\mathrm{M}_{1}, \mathrm{M}_{2}\right)= \\
\pi\left(\mathrm{M}_{1}, \mathrm{M}_{2}, \theta_{1}, \mathrm{~h}\right)
\end{gathered}
$$

where $P_{o}, P_{1}, P_{2}$ are the base prices of the output and the two inputs, and $r_{o}, r_{1}$ and $r_{2}$ are the constant transport rates for output and the two inputs, respectively. Distances from the production location to the sources $M_{1}, M_{2}$ and to the market are ${ }_{1} \mathrm{~S},{ }_{2} \mathrm{~S}$, and $\mathrm{h}$, respectively. The angle between the straight lines from the market to $M_{1}$ and from the market to the production location is $\theta_{1}$.

\section{THE MODEL}

Under conditions of perfect competition $\mathrm{P}_{\mathrm{o}}, \mathrm{P}_{1}$ and $\mathrm{P}_{2}$ are constant and the profit maximizing location conditions are:

$$
\begin{aligned}
\frac{\partial \pi}{\partial M_{1}} & =P_{o} F_{1}-\left(P_{1}+r_{11} S\right)-r_{o} h F_{1}=\left(P_{o}-r_{o} h\right) F_{1} \\
- & \left(P_{1}+r_{11} S\right)=0 \\
\frac{\partial \pi}{\partial M_{2}} & =P_{o} F_{2}-\left(P_{2}+r_{22} S\right)-r_{o} h F_{2}=\left(P_{o}-r_{o} h\right) F_{2} \\
- & \left(P_{2}+r_{22} S\right)=0 \\
\frac{\partial \pi}{\partial \theta_{1}} & =-r_{1} M_{11} S_{\theta_{1}}-r_{2} M_{22} S_{\theta_{1}}=0
\end{aligned}
$$




$$
\frac{\partial \pi}{\partial \mathrm{h}}=-\mathrm{r}_{1} \mathrm{M}_{11} \mathrm{~S}_{\mathrm{h}}-\mathrm{r}_{2} \mathrm{M}_{22} \mathrm{~S}_{\mathrm{h}}-\mathrm{r}_{\mathrm{o}} \mathrm{F}\left(\mathrm{M}_{1}, \mathrm{M}_{2}\right)=0
$$

where $\mathrm{F}_{1}, \mathrm{~F}_{2}, \mathrm{~S}_{\theta_{1},}, \mathrm{~S}_{\theta_{1}},{ }_{1} \mathrm{~S}_{\mathrm{h}}$ and ${ }_{2} \mathrm{~S}_{\mathrm{h}}$ are first partial derivatives. The profit maximizing conditions require that (a) net values of marginal product (net of per unit output transport costs) for each of the two inputs must equal their respective delivered prices, and (b) that marginal transport cost with respect to each of the two locational coordinates must equal zero.

In order to determine the effect of various exogenous variables on the profit maximizing production location, we must find total differentials of (2) - (5). These total differentials are:

$$
\begin{aligned}
& \left(P_{o}-r_{o} h\right) F_{11} d M_{1}+\left(P_{o}-r_{o} h\right) F_{12} d M_{2}-r_{11} S_{\theta_{1}} d \theta_{1} \\
& -\left(\mathrm{r}_{\mathrm{o}} \mathrm{F}_{1}+\mathrm{r}_{11} \mathrm{~S}_{\mathrm{h}}\right) \mathrm{dh}=-\mathrm{F}_{1} \mathrm{dP}_{\mathrm{o}}+\mathrm{F}_{1} \mathrm{hdr}_{\mathrm{o}}+\mathrm{dP}_{1}+{ }_{1} \mathrm{Sdr}_{1} \\
& \left(\mathrm{P}_{\mathrm{o}}-\mathrm{r}_{\mathrm{o}} \mathrm{h}\right) \mathrm{F}_{12} \mathrm{dM} \mathrm{M}_{1}+\left(\mathrm{P}_{\mathrm{o}}-\mathrm{r}_{\mathrm{o}} \mathrm{h}\right) \mathrm{F}_{22} \mathrm{dM}_{2}-\mathrm{r}_{22} \mathrm{~S}_{\theta_{1}} \mathrm{~d} \theta_{1} \\
& -\left(\mathrm{r}_{2} \mathrm{~F}_{2}+\mathrm{r}_{2} \mathrm{~S}_{\mathrm{h}}\right) \mathrm{dh}=-\mathrm{F}_{2} \mathrm{dP}_{\mathrm{o}}+\mathrm{F}_{2} \mathrm{hdr}_{\mathrm{o}}+\mathrm{dP}_{2}+{ }_{2} \mathrm{Sdr}_{2} \\
& -\mathrm{r}_{11} \mathrm{~S}_{\theta_{1}} \mathrm{dM} \mathrm{M}_{1}-\mathrm{r}_{2} \mathrm{~S}_{\theta_{1}} \mathrm{dM} \mathrm{M}_{2}-\mathrm{C}_{\theta_{1} \theta_{1}} \mathrm{~d} \theta_{1}-\mathrm{C}_{\theta_{1} \mathrm{~h}} \mathrm{dh} \\
& =\mathrm{M}_{11} \mathrm{~s}_{\theta_{1}} \mathrm{dr}_{1}+\mathrm{M}_{22} \mathrm{~s}_{\theta_{1}} \mathrm{dr}_{2} \\
& -\left(\mathrm{r}_{\mathrm{o}} \mathrm{F}_{1}+\mathrm{r}_{11} \mathrm{~S}_{\mathrm{h}}\right) \mathrm{dM} \mathrm{M}_{1}-\left(\mathrm{r}_{\mathrm{o}} \mathrm{F}_{2}+\mathrm{r}_{22} \mathrm{~S}_{\mathrm{h}}\right) \mathrm{dM}_{2}-\mathrm{C}_{\theta_{1} \mathrm{~h}} \mathrm{~d} \theta_{1}-\mathrm{C}_{\mathrm{hh}} \mathrm{dh}= \\
& \mathrm{M}_{11} \mathrm{~S}_{\mathrm{h}} \mathrm{dr}_{1}+\mathrm{M}_{22} \mathrm{~S}_{\mathrm{h}} \mathrm{dr}_{2}+\mathrm{Fdr}_{\mathrm{o}}
\end{aligned}
$$

where:

$$
\begin{aligned}
& \mathrm{C}_{\theta_{1} \theta_{1}}=\mathrm{r}_{1} \mathrm{M}_{11} \mathrm{~S}_{\theta_{1} \theta_{1}}+\mathrm{r}_{2} \mathrm{M}_{22} \mathrm{~S}_{\theta_{1} \theta_{1}} \\
& \mathrm{C}_{\theta_{1} \mathrm{~h}}=\mathrm{r}_{1} \mathrm{M}_{11} \mathrm{~S}_{\theta_{1} \mathrm{~h}}+\mathrm{r}_{2} \mathrm{M}_{22} \mathrm{~S}_{\theta_{1} \mathrm{~h}} \\
& \mathrm{C}_{\mathrm{hh}}=\mathrm{r}_{1} \mathrm{M}_{11} \mathrm{~S}_{\mathrm{hh}}+\mathrm{r}_{2} \mathrm{M}_{22} \mathrm{~S}_{\mathrm{hh}}
\end{aligned}
$$

and $F_{11}, F_{12}, F_{22}$ are second partials of $F$.

A. Analysis of the location problem with prior constraint on the location distance

Proposition 1: Assuming $\mathrm{h}$ is a positive constant, and $\theta_{1}$ is a variable $\left(\theta_{1}<\right.$ $\theta$ ), the firm's production location is independent of the output price level, and output transport rate, if and only if the expansion path is linear.

Proof: Using the system of equation (6) - (8) with $\mathrm{dh}, \mathrm{dr}_{\mathrm{o}}, \mathrm{dr}_{1}, \mathrm{dr}_{2}, \mathrm{dP}_{1}$ and $\mathrm{dP}_{2}=0$, one obtains: 


$$
\frac{\partial \theta_{1}}{\partial \mathrm{P}_{\mathrm{o}}}=\frac{1}{\mathrm{D}^{*}}\left|\begin{array}{ccc}
\mathrm{P}_{\mathrm{o}}^{\prime} \mathrm{F}_{11} & \mathrm{P}_{\mathrm{o}}^{\prime} \mathrm{F}_{12} & -\mathrm{F}_{1} \\
\mathrm{P}_{\mathrm{o}}^{\prime} \mathrm{F}_{12} & \mathrm{P}_{\mathrm{o}}^{\prime} \mathrm{F}_{22} & -\mathrm{F}_{2} \\
-\mathrm{r}_{11} \mathrm{~S}_{\theta_{1}} & -\mathrm{r}_{22} \mathrm{~S}_{\theta_{1}} & 0
\end{array}\right|
$$

where $\mathrm{D}^{*}<0$, the highest order relevant Hessian determinant of the second order condition, and $\mathrm{P}_{\mathrm{o}}^{\prime}=\left(\mathrm{P}_{\mathrm{o}}-\mathrm{r}_{\mathrm{o}} \mathrm{h}\right)$. Multiplying the first column by $\mathrm{M}_{1}$, the second column by $\mathrm{M}_{2}$, adding the second resulting column to the first and simplifying, we obtain:

$$
\frac{\partial \theta_{1}}{\partial \mathrm{P}_{\mathrm{o}}}=\frac{\mathrm{r}_{22} \mathrm{~S}_{\theta_{1}} \mathrm{P}_{\mathrm{o}}^{\prime}}{\mathrm{D}^{*} \mathrm{M}_{1}}\left[\mathrm{~F}_{2}\left(\mathrm{M}_{1} \mathrm{~F}_{11}+\mathrm{M}_{2} \mathrm{~F}_{12}\right)-\mathrm{F}_{1}\left(\mathrm{M}_{1} \mathrm{~F}_{12}+\mathrm{M}_{2} \mathrm{~F}_{22}\right)\right]
$$

since $r_{2}>0, P_{o}^{\prime}>0, M_{1}>0, D^{*}<0$ and ${ }_{2} S_{\theta_{1}}<0$, then $\frac{\partial \theta_{i}}{\partial P_{o}}=0$ if and only if

$$
\frac{M_{2}}{M_{1}}=\frac{F_{2} F_{11}-F_{1} F_{12}}{F_{1} F_{22}-F_{2} F_{12}}
$$

Equation (13) is true if and only if the expansion path is linear through the origin (see Appendix A).

To show that the firm's location is independent of output transport rate we perform similar operations on the system of equations (6) - (8) to find that:

$$
\frac{\partial \theta_{1}}{\partial \mathrm{r}_{\mathrm{o}}}=\frac{\mathrm{h}}{\mathrm{D}^{*}}\left|\begin{array}{ccc}
\mathrm{P}_{\mathrm{O}}^{\prime} \mathrm{F}_{11} & \mathrm{P}_{\mathrm{o}}^{\prime} \mathrm{F}_{12} & \mathrm{~F}_{1} \\
\mathrm{P}_{\mathrm{O}}^{\prime} \mathrm{F}_{12} & \mathrm{P}_{\mathrm{O}}^{\prime} \mathrm{F}_{22} & \mathrm{~F}_{2} \\
-\mathrm{r}_{11} \mathrm{~S}_{\theta_{1} \theta_{1}} & -\mathrm{r}_{22} \mathrm{~S}_{\theta_{1}} & 0
\end{array}\right|=0
$$

if and only if the expansion path is linear through the origin. We conclude that location is independent of either output price, $\mathrm{P}_{\mathrm{o}}$, or output transport rate, $\mathrm{r}_{\mathrm{o}}$, if and only if the expansion path is linear.

Proposition 2: Assuming $\mathrm{h}$ is a positive constant and $\theta$ is a variable $\left(\theta_{1}<\theta\right)$, as the output base price decreases, the firm's production location would swing toward the input source $M_{1}\left(M_{2}\right)$ if and only if $M_{1}\left(M_{2}\right)$ increases relative to $\mathrm{M}_{2}\left(\mathrm{M}_{1}\right)$ along the expansion path in the input space. Proof: From proposition 1 for $\mathrm{dh}=0$, the sign of $\frac{\partial \theta_{1}}{\partial \mathrm{P}_{\mathrm{o}}}$ is the same as the
sign of: 


$$
\mathrm{N}^{\prime}=\mathrm{F}_{2}\left(\mathrm{M}_{1} \mathrm{~F}_{11}+\mathrm{M}_{2} \mathrm{~F}_{12}\right)-\mathrm{F}_{1}\left(\mathrm{M}_{1} \mathrm{~F}_{12}+\mathrm{M}_{2} \mathrm{~F}_{22}\right)
$$

Therefore, $\frac{\partial \theta_{1}}{\partial \mathrm{P}_{\mathrm{o}}}>0(<0)$ if and only if $\mathrm{N}^{\prime}>0(<0)$. However, $\mathrm{N}^{\prime}>0$ $(<0)$ if and only if $M_{1}\left(M_{2}\right)$ increases relative to $M_{2}\left(M_{1}\right)$ along the expansion path in the input space (see Appendix B). This proposition states that location moves toward a resource site if and only if that resource increases relative to the other along the expansion path.

Proposition 3: Assume $\mathrm{h}$ is a positive constant and $\theta_{1}$ is a variable $\left(\theta_{1}<\theta\right)$, as the output transport rate increases, the firm's production location would swing toward the input source $M_{1}\left(M_{2}\right)$ if and only if $M_{1}\left(M_{2}\right)$ increases relative to $\mathrm{M}_{2}\left(\mathrm{M}_{1}\right)$ along the expansion path, holding relative prices and other variables constant.

Proof: Using the system of equations (6) - (8) holding dh constant, using the Cramer's rule and simplifying, we obtain:

$$
\frac{\partial \theta_{1}}{\partial r_{0}}=\frac{-r_{22} S \theta_{1} P_{0}^{\prime} h}{D^{*} M_{1} M_{2}}\left[F_{2}\left(M_{1} F_{11}+M_{2} F_{12}\right)-F_{1}\left(M_{1} F_{12}+M_{2} F_{22}\right)\right]
$$

The sign of $\frac{\partial \theta_{1}}{\partial \mathrm{r}_{\mathrm{o}}}$ is opposite that of $\mathrm{N}^{\prime}$ in proposition 1. Therefore, $\frac{\partial \theta_{1}}{\partial \mathrm{r}_{\mathrm{o}}}<0$ $(>0)$ if and only if $\mathrm{N}^{\prime}>0(<0)$. However, $\mathrm{N}^{\prime}>0(<0)$ if and only if $M_{1}\left(M_{2}\right)$ increases relative to $M_{2}\left(M_{1}\right)$ along the expansion path (see Appendix B). We conclude that location moves toward a resource site as the output transport rate increases if and only if that resource increases relative to the others along the expansion path.

Proposition 4: Assuming $\mathrm{h}$ is a positive constant, $\theta_{1}$ is a variable $\left(\theta_{1}<\theta\right)$, and the production function is homogeneous of degree $n$, the firm's optimum production location would swing toward $\mathrm{M}_{2}\left(\mathrm{M}_{1}\right)$ as $\mathrm{P}_{1}\left(\mathrm{P}_{2}\right)$, the input base price associated with $\mathrm{M}_{1}\left(\mathrm{M}_{2}\right)$, increases.

Proof: Using the system of equations (6) - (9), holding h constant and simplifying, we obtain:

$$
\frac{\partial \theta_{1}}{\partial P_{1}}=\frac{-P_{0}^{\prime} r_{2} M_{22} S_{\theta_{1}}}{D^{*} M_{1} M_{2}}\left(M_{1} F_{12}+M_{2} F_{22}\right)=\frac{-P_{0}^{\prime} r_{22} S_{\theta_{1}}(n-1) F_{2}}{D^{*} M_{1}}
$$

(using the fact that marginal products are homogeneous of degree $(n-1)$ and that second order condition requires that $\mathrm{n}$ be less than ).

$$
\text { Since } D^{*}<0,{ }_{2} S_{\theta_{1}}<0,(n-1)<0 \text {, and } P_{0}, r_{2}, M_{1}, F_{2}>0 \text {, then } \frac{\partial \theta_{1}}{\partial P_{1}}
$$


$>0$. Similarly, it can be shown that $\frac{\partial \theta_{1}}{\partial \mathrm{P}_{2}}<0$ and we conclude that location moves toward a resource site as the price of the other resource increases if and only if the production function is homogeneous of degree $n$.

B. Analysis of the location problem with no prior constraint on the location distance.

Proposition 5: If $\mathrm{h}>0, \theta_{1}<\theta$ are both variables and the production function is homogeneous, then the production location would move away from the market as the output base price $P_{o}$ increases.

Proof: Using Cramer's rule on the system of equations (6) - (8), the properties of homogeneity and simplifying, we obtain:

$$
\begin{aligned}
\frac{\partial \mathrm{h}}{\partial \mathrm{P}_{\mathrm{o}}}= & \frac{-\mathrm{r}_{\mathrm{o}} \mathrm{n}(\mathrm{n}-1) \mathrm{q}^{2}}{\mathrm{DM}_{1}^{2} \mathrm{M}_{2}^{2}}\left[-\mathrm{C}_{\theta_{1} \theta_{1}} \mathrm{P}_{\mathrm{o}}^{\prime}\left[\mathrm{M}_{2}^{2} \mathrm{~F}_{22} \mathrm{nq}-\mathrm{M}_{2} \mathrm{~F}_{2}\left(\mathrm{M}_{1} \mathrm{M}_{2} \mathrm{~F}_{12}+\mathrm{M}_{2}^{2} \mathrm{~F}_{22}\right)\right]\right. \\
& \left.-\mathrm{nq}\left(\mathrm{r}_{2} \mathrm{M}_{22} \mathrm{~S}_{\theta_{1}}\right)^{2}\right]
\end{aligned}
$$

Since, from the second order condition, $(n-1)<0$, the term inside brackets [ ] is positive, and D $>0$, therefore:

$$
\frac{\partial \mathrm{h}}{\partial \mathrm{P}_{\mathrm{O}}}>0
$$

This result indicates that when the distance from the market is a variable and the production function is homogeneous of degree $n$, location moves away from the market as output price increases.

Proposition 6: If $\mathrm{h}>0, \theta_{1}<\theta$ are both variables and the production function is homogeneous of degree $\mathrm{n}$, then the production location would move toward the market as output transport rate increases.

Proof: Using the same procedures as in previous proposition and its results we find that:

$$
\frac{\partial \mathrm{h}}{\partial \mathrm{r}_{\mathrm{o}}}=\frac{\mathrm{r}_{\mathrm{o}} \mathrm{q}_{\mathrm{o}}(\mathrm{n}-1)}{\mathrm{DM}_{1}^{2} \mathrm{M}_{2}^{2}}\left|\begin{array}{ccc}
\mathrm{P}_{\mathrm{o}}^{\prime} \mathrm{M}_{2}(\mathrm{n}-1) \mathrm{F}_{2} & 0 & \text { hnq } \\
\mathrm{P}_{\mathrm{o}}^{\prime} \mathrm{M}_{2}^{2} \mathrm{~F}_{22} & -\mathrm{r}_{2} \mathrm{M}_{22} \mathrm{~S}_{\theta_{1}} & \mathrm{hM}_{2} \mathrm{~F}_{2} \\
-\mathrm{r}_{2} \mathrm{M}_{22} \mathrm{~S}_{\theta_{1}} & -\mathrm{C}_{\theta_{1} \theta_{1}} & 0
\end{array}\right|<0
$$

We conclude that if distance from the market is a variable and the production function is homogeneous of degree $\mathrm{n}$, location moves toward the market as output transport rate increases. 


\section{SUMMARY OF THE RESULTS}

This paper has used the method presented by Khalili, et al. [4] to analyze the effect of changes in variables in a Moses-type production-location problem on location decision of a profit maximizing firm. The results were obtained under two different situations: (a) when the distance from the market is fixed, and (b) when this distance is a variable. The following results were obtained:

(i) When the distance from market is fixed, location is shown to be independent of the output price if and only if the expansion is linear.

(ii) Under the same conditions as in (i) location is also shown to be independent of the output transport rate.

(iii) When the distance from the market is fixed, location moves toward a resource site if and only if that resource increases relative to the other along the expansion path in the input space.

(iv) When the distance from the market is fixed, as the output transport rate increases, location moves toward a resource site if and only if that resource increases relative to the other along the expansion path in the input space.

(v) When the distance from the market is fixed and the production function is homogeneous of degree $\mathrm{n}$, location is shown to move toward a resource site as the price of the other resource increases.

(vi) When the distance from the market is not fixed and the production function is homogeneous, location moves away from the market as the output price increases.

(vii) Under the same conditions as in (vi) location moves toward the market as output transport rate increases. 


$$
\mathrm{N}^{\prime}=0 \text { if and only if } \frac{\mathrm{M}_{2}}{\mathrm{M}_{1}}=\frac{\mathrm{F}_{2} \mathrm{~F}_{11}-\mathrm{F}_{1} \mathrm{~F}_{12}}{\mathrm{~F}_{1} \mathrm{~F}_{22}-\mathrm{F}_{2} \mathrm{~F}_{12}}
$$

If we define $\frac{F_{2}}{F_{1}}=H\left(M_{1}, M_{2}\right)$ as the slope of the isoquant along the expansion path, then,

$$
\begin{aligned}
& \frac{\partial H}{\partial M_{1}}=\frac{F_{1} F_{12}-F_{2} F_{11}}{F_{1}^{2}} \\
& \frac{\partial H}{\partial M_{2}}=\frac{F_{1} F_{22}-F_{2} F_{12}}{F_{1}^{2}} \\
& \frac{\partial H / \partial M_{1}}{\partial H / \partial M_{2}}=\frac{F_{1} F_{12}-F_{2} F_{11}}{F_{1} F_{22}-F_{2} F_{12}}=-\frac{d M_{2}}{d M_{1}}
\end{aligned}
$$

Therefore,

$$
\frac{d M_{2}}{d M_{1}}=\frac{F_{2} F_{11}-F_{1} F_{12}}{F_{1} F_{22}-F_{2} F_{12}}
$$

From equations (1) and (5), we have:

$$
\frac{\mathrm{dM}_{2}}{\mathrm{dM}_{1}}=\frac{\mathrm{M}_{2}}{\mathrm{M}_{1}}
$$

Equation (6) is that of a linear expansion path. 


$$
\begin{gathered}
\text { APPENDIX B } \\
\mathrm{N}^{\prime}=\mathrm{M}_{1} \mathrm{~F}_{2} \mathrm{~F}_{11}+\mathrm{M}_{2} \mathrm{~F}_{2} \mathrm{~F}_{12}-\mathrm{M}_{2} \mathrm{~F}_{1} \mathrm{~F}_{22}-\mathrm{M}_{1} \mathrm{~F}_{1} \mathrm{~F}_{12}
\end{gathered}
$$

Equation (7) can be written as:

$$
N^{\prime}=M_{1}\left(F_{2} F_{11}-F_{1} F_{12}\right)-M_{2}\left(F_{1} F_{22}-F_{2} F_{12}\right)>0
$$

For a general production function using two inputs, only one of the inputs could be inferior, i.e., when $\mathrm{M}_{2}$ is inferior $\mathrm{F}_{2} \mathrm{~F}_{11}-\mathrm{F}_{1} \mathrm{~F}_{12}>0$. Therefore, when $M_{1}$ is superior, i.e., $F_{1} F_{22}-F_{2} F_{12}<0, N^{\prime}>0$ if and only if:

$$
\frac{M_{2}}{M_{1}}>\frac{F_{2} F_{11}-F_{1} F_{12}}{F_{1} F_{22}-F_{2} F_{12}}
$$

From equation (5) of Appendix A, it follows:

$$
\frac{\mathrm{M}_{2}}{\mathrm{M}_{1}}>\frac{\mathrm{dM}_{2}}{\mathrm{dM}_{1}}
$$

Therefore, the firm's location will move toward $M_{1}$ if and only if the $M_{1}$ increases relative to $\mathrm{M}_{2}$ along the expansion path.

Similarly, in the event $\mathbf{M}_{2}$ is superior, $\mathbf{N}^{\prime}<0$ if and only if

$$
\frac{M_{2}}{M_{1}}<\frac{d M_{2}}{d M_{1}}
$$

Which implies that the firm's location will move toward $M_{2}$ if and only if $M_{2}$ is used more intensively along the expansion path. When both $M_{1}$ and $M_{2}$ are superior, $\mathbf{N}^{\prime}>0$ if and only if condition (9) holds. The converse is true when condition (10) holds. 


\section{REFERENCES}

[1] BRADFIELD, M., "A Note on Location and the Theory of Production," Journal of Regional Science, 11: 263-266 (1971).

[2] EMERSON, D. L., "Optimum Firm Location and the Theory of Production," Journal of Regional Science, 13: 335-347 (1973).

[3] ISARD, W., Location and Space - Economy, New York: MIT Press and John Wiley, 1956, pp. 77-90.

[4] KHALILI, AMIR, ET AL., "Location and the Theory of Production: A Generalization," Journal of Economic Theory, 9: 467-475 (1974).
[5] MILLER, STEPHEN M. AND JENSEN, OSCAR W., "Location and the Theory of Production," Regional Science and Urban Economics, 8: 117-128 (1978).

[6] MOSES, L. N., "Location and the Theory of Production," Quarterly Journal of Economics, 72: 259-272 (1958).

[7] SAKASHITA, N., "Production Function, Demand Function and Location Theory of Firm," Papers, Regional Science Association, 20: 109-122 (1967).

[8] WEBER, A., $A$ Theory of Location of Industries, (C. J. Friedrich, trans.) Chicago: University of Chicago Press, 1962. 